\title{
BMJ Open Validation of an automated delirium prediction model (DElirium MOdel (DEMO)): an observational study
}

\author{
Carlota Mestres Gonzalvo, ${ }^{1,2}$ Hugo A J M de Wit, ${ }^{1,3}$ Brigit P C van Oijen, ${ }^{1}$ \\ Debbie S Deben, ${ }^{1}$ Kim P G M Hurkens, ${ }^{4}$ Wubbo J Mulder, ${ }^{5}$ Rob Janknegt, ${ }^{1}$ \\ Jos M G A Schols, ${ }^{6}$ Frans R Verhey, ${ }^{7}$ Bjorn Winkens, ${ }^{8}$ Paul-Hugo M van der Kuy ${ }^{1,9}$
}

To cite: Mestres Gonzalvo C, de Wit HAJM, van Oijen BPC, et al. Validation of an automated delirium prediction model (DElirium MOdel (DEMO)): an observational study. BMJ Open 2017;7:e016654. doi:10.1136/ bmjopen-2017-016654

- Prepublication history and additional material for this paper are available online. To view these files, please visit the journal online (http://dx.doi. org/10.1136/bmjopen-2017016654).

Received 10 March 2017 Revised 6 October 2017 Accepted 9 0ctober 2017

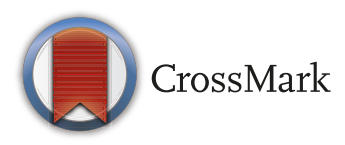

For numbered affiliations see end of article.

\section{Correspondence to} Carlota Mestres Gonzalvo; c.mestresgonzalvo@zuyderland. $\mathrm{nl}$

\section{ABSTRACT}

Objectives Delirium is an underdiagnosed, severe and costly disorder, and $30 \%-40 \%$ of cases can be prevented. A fully automated model to predict delirium (DEMO) in older people has been developed, and the objective of this study is to validate the model in a hospital setting.

Setting Secondary care, one hospital with two locations. Design Observational study.

Participants The study included 450 randomly selected patients over 60 years of age admitted to Zuyderland Medical Centre. Patients who presented with delirium on admission were excluded.

Primary outcome measures Development of delirium through chart review.

Results A total of 383 patients were included in this study. The analysis was performed for delirium within 1, 3 and 5 days after a DEM0 score was obtained. Sensitivity was $87.1 \%$ (95\% Cl 0.756 to 0.939$), 84.2 \%$ (95\% Cl 0.732 to 0.915$)$ and $82.7 \%(95 \% \mathrm{Cl} 0.734$ to 0.893$)$ for 1,3 and 5 days, respectively, after obtaining the DEM0 score. Specificity was $77.9 \%$ (95\% Cl 0.729 to 0.882 ), $81.5 \%$ (95\% Cl 0.766 to 0.856$)$ and $84.5 \%$ (95\% Cl 0.797 to 0.884 ) for 1,3 and 5 days, respectively, after obtaining the DEM0 score.

Conclusion DEMO is a satisfactory prediction model but needs further prospective validation with in-person delirium confirmation. In the future, DEMO will be applied in clinical practice so that physicians will be aware of when a patient is at an increased risk of developing delirium, which will facilitate earlier recognition and diagnosis, and thus will allow the implementation of prevention measures.

\section{INTRODUCTION}

A delirium or acute confused state is a transient attention and cognition disorder that develops over a short period of time and occurs mainly in hospitalised patients and people aged 60 years and over. Delirium is an underdiagnosed, severe (increased mortality), costly and often preventable disorder. $^{1-3}$ Its severity and symptoms can vary considerably, but the main features are impaired cognitive and sensory functions, reduced consciousness and diminished

\section{Strengths and limitations of this study}

A high risk of delirium can be predicted electronically by using DEMO (DElirium MOdel) with reasonably good sensitivity and specificity.

- DEM0 can be applied in clinical practice to facilitate earlier recognition and diagnosis of delirium.

- Important factors that could predict delirium (previous delirium, cognitive impairment, severity of disease, visual impairment, etc) are not included in this model because these data are not yet electronically available.

attention. In addition, it is often accompanied by problems with psychomotor activity, the circadian rhythm and emotions.

The prevalence and incidence of delirium in the general population differ widely depending on the setting. The overall prevalence in the community is estimated to be $1 \%-2 \%$. In a hospital setting, this prevalence increases to $10 \%-31 \%$ at the time of hospital admission and 3\%-29\% during hospitalisation. The incidence increases up to $87 \%$ when more specialised populations, such as the elderly and people in postoperative, intensive care and/or palliative care, are considered. $^{4-11}$ In $30 \%-40 \%$ of cases, delirium is preventable, which, along with its associated high costs (ranging from US\$164 billion to US $\$ 182$ billion per year), makes it a perfect target for interventions by healthcare professionals. ${ }^{14}$ 12-15 As a result, a great number of screening tools have been developed and are widely used to detect the early onset of delirium, which can in turn allow treatment measures to be introduced in a timely manner. ${ }^{16-21}$ These tools help healthcare professionals to establish and quantify symptoms associated with delirium. ${ }^{19-23}$ Once the diagnosis has been established, the underlying medical condition can be targeted, and delirium can be managed appropriately. 


\section{Box DElirium MOdel (DEMO) and cut-off point}

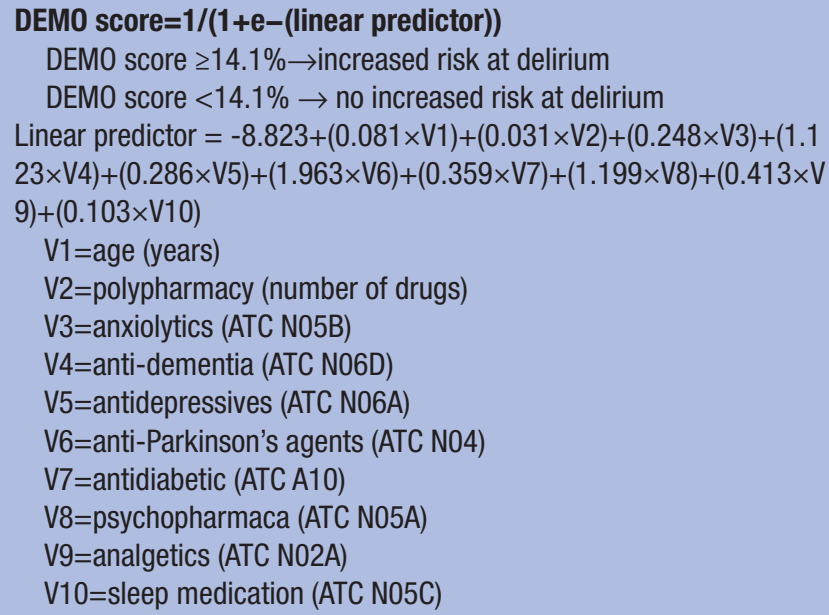

ATC, Anatomical Therapeutic Chemical classification system (https://www. whocc.no/atc_ddd_index/).

There is no effective treatment for delirium. ${ }^{24} 25$ Preventing delirium is by far a more effective strategy to improve patient outcomes. ${ }^{146-29}$ Risk models have been used to identify patients at higher risk for delirium development because these patients would most likely benefit from delirium prevention. These models are based on manual evaluation of individual risk factors and may be difficult to implement, so automated models are preferable and more feasible. ${ }^{30-34}$

\section{Screening instrument}

A fully automated model to predict delirium in older people (aged over 60 years) was developed at Zuyderland Medical Centre. This DElirium MOdel (DEMO) uses only electronically available data to predict the occurrence of delirium. The predictive variables include age, polypharmacy and the use of antidementia drugs, antidepressants, anti-Parkinson's agents, antidiabetic drugs, analgesia and/ or sleeping tablets (see box). This model can be applied hospital-wide and has an area under receiver operating characteristic (measure for model prediction quality) value of 0.770 (95\% CI 0.736 to 0.804$)$ with a sensitivity of $78.2 \%$ and a specificity of $63.7 \%$, when $14.1 \%$ is used as a cut-off value for the predicted probability of developing delirium. DEMO was developed retrospectively but has not yet been validated. ${ }^{4}$

Therefore, the objective of this study is to validate DEMO in a hospital setting. To do so, the system's accuracy (main study parameter), that is, sensitivity (proportion of delirium patients who test positive) and specificity (proportion of non-delirium patients who test negative), will be calculated. In addition to these parameters, the positive predictive value (PPV), negative predictive value (NPV), positive and negative likelihood ratios (LR+, LR-) with their $95 \%$ CI will be computed.

\section{METHODS}

This is an observational study of the ability of DEMO to predict delirium in an elderly hospital population. It was conducted in Zuyderland Medical Centre (locations Sittard and Heerlen) in the period from January 2016 to October 2016.

DEMO involves a daily analysis of all hospitalised patients aged $\geq 60$ years at the different wards and predicts whether a patient is at risk of developing delirium in a 24-hour postanalysis period. The electronic patient record (EPR) was accessed at a later date to check for delirium diagnosis. In this study, DEMO was calculated prospectively, but the outcome was ascertained by chart review retrospectively.

Although delirium diagnosis was determined by chart review, delirium documentation in our hospital is robust. At admission, patients are routinely screened for delirium, both in the emergency department and in the ward. The first screening is performed by a checklist (Inspectie voor de Gezondheidszorg=Dutch Healthcare Inspectorate, Veiligheids management systeem=Safety Management System and Dutch guideline for delirium) ${ }^{35} 36$ This checklist consists of three questions: does the patient need help with self-care?, has the patients previously suffered a delirium?, does the patients suffer from memory disorders? When one of the questions is positively answered, the patient is at risk of developing delirium; in this case, the Delirium Observation Screening Scale (DOSS) method ${ }^{20}$ is used to evaluate whether a patient has delirium and it is subsequently noted in the chart.

Patients aged over 60 years who were admitted to Zuyderland were eligible for enrolment. From all patients admitted between 31 December 2015 and 31 October 2016, 450 patients were randomly selected (using https://www.randomlists.com/team-generator) and their charts extracted for review. Patients who, based on chart review, presented with delirium on admission were then excluded (see online supplementary figure 1).

A search in the EPR was performed according to patient and date by using the following search terms: 'delirium', 'delirious', 'agitation', 'agitated', 'confused', 'confusion', 'restlessness', 'disturbed', 'disorientation', 'disoriented', 'apathy', 'hallucination', 'mistrust', 'haloperidol' and 'delirium prevention measures'. These search terms were discussed with an internist geriatrician, a professor of geriatric medicine and a professor of geriatric psychiatry.

The search was performed by first identifying where the different words appeared in the EPR, and then, if any of these words appeared, the whole EPR during the admission period was read and interpreted by two authors (KH (internist geriatrician) and CMG (hospital pharmacist)) to determine whether it was truly a delirium diagnosis. All notes were reviewed, including notes by physicians, nurses, physiotherapists and speech therapists. During the study, treating healthcare professionals (physicians, nurses, etc) were blinded to DEMO scores in order to avoid bias. If a diagnosis of delirium could not be established for a patient as a result of insufficient information 
Table 1 Test results of the prediction model (DEMO positive or negative) and diagnosis (delirium during admission or no delirium during admission) within 1, 3 and 5 days after DEMO analysis

\begin{tabular}{lllllll}
\hline & $\begin{array}{l}\text { Delirium } \\
\text { within 1 day } \\
\text { after DEMO }\end{array}$ & $\begin{array}{l}\text { No delirium } \\
\text { within } \\
\text { 1 day after DEMO }\end{array}$ & $\begin{array}{l}\text { Delirium } \\
\text { within 3 days } \\
\text { after DEMO }\end{array}$ & $\begin{array}{l}\text { No delirium } \\
\text { within 3 days } \\
\text { after DEMO }\end{array}$ & $\begin{array}{l}\text { Delirium } \\
\text { within 5days } \\
\text { after DEMO }\end{array}$ & $\begin{array}{l}\text { No delirium } \\
\text { within 5 days } \\
\text { after DEMO }\end{array}$ \\
\hline DEMO positive & 54 & 71 & 69 & 56 & 81 & 44 \\
DEMO negative & 8 & 250 & 11 & 247 & 17 & 241 \\
\hline
\end{tabular}

DEMO, DElirium MOdel.

in the chart, this patient was excluded from the analysis. The date of delirium onset was determined by chart review.

Delirium diagnosis based on chart review was then compared with the risk score from DEMO. The DEMO was dichotomised into two groups: high risk $\geq 14.1 \%,{ }^{4}$ and low risk $<14.1 \%$ for this analysis. A two-by-two table was then constructed to calculate true positive (TP), true negative $(\mathrm{TN})$, false positive $(\mathrm{FP})$ and false negative $(\mathrm{FN})$ rates.

The predictive value of DEMO was determined for delirium developing within 1, 3 and 5 days after the DEMO score was calculated. It had been developed to predict delirium within the next 24 hours, but here we wished to also investigate whether its predictive value could be extended to 3 or 5 days.

In the study wherein the DEMO was developed, an incidence rate of $17.4 \%$ was used. ${ }^{4}$ Given the assumption of the same sensitivity of $0.75(75 \%)$, we calculated that 33 delirium patients were needed based on the requirement that the lower limit of $95 \%$ CI would be at least $60 \%$ (width of $95 \% \mathrm{CI} \leq 0.30(30 \%)$ ). With regard to the specificity, the number of non-delirium patients would be much larger than the number of delirium patients, and hence, the width of the $95 \%$ CI for specificity would be $<0.30$.

It was assumed that at least 332 patients would be needed to identify 33 delirium patients. Taking into account the exclusion criteria and the possibility of a smaller percentage of patients who would develop delirium, a sufficient number of patients were screened to obtain 33 delirium patients (ie, 450 patients).

The sensitivity, specificity, PPV, NPV, LR+, LR- with corresponding $95 \%$ CIs were calculated with the use of an online calculator (http://vassarstats.net/clin1.html).

The differences in PPV and NPV over time were tested using McNemar's test. The differences in age and gender between delirium and non-delirium groups were tested by using the independent-samples t-test and $\chi^{2}$ test, respectively. IBM SPSS statistics for Windows (V.23.0) was used to perform these tests. A two-sided $\mathrm{p} \leq 0.05$ was considered statistically significant.

\section{RESULTS}

The study lasted 8 months, for 450 patients chart review was undergone. Finally, a total of 383 patients were included, as 21 patients presented with delirium at admission, and for 46 patients there was insufficient information to determine delirium status (see online supplementary figure 1). The results of the diagnostic test (TP/FP/FN/ TN) for 1, 3 and 5 days after DEMO analysis are shown in table 1 . The analysis, including prevalence estimates, sensitivity, specificity, PPV, NPV and LRs, is presented in table 2. Although sensitivity decreased and specificity increased if the period increased from 1 day to 3 or 5 days after DEMO score was obtained, all values were rather high (sensitivity $\geq 0.827$, specificity $\geq 0.779$ ). PPV was statistically different $\mathrm{p}<0.001$ for all three comparisons (1 vs

Table 2 Estimates of the prevalence, sensitivity, specificity, PPV, NPV and LRs with corresponding 95\% Cls 1, 3 and 5 days after DEMO analysis

\begin{tabular}{|c|c|c|c|c|c|c|c|c|c|}
\hline & \multicolumn{3}{|c|}{ Day 1 after DEMO analysis } & \multicolumn{3}{|c|}{ Day 3 after DEMO analysis } & \multicolumn{3}{|c|}{ Day 5 after DEMO analysis } \\
\hline & \multirow[b]{2}{*}{$\begin{array}{l}\text { Estimated } \\
\text { value }\end{array}$} & \multicolumn{2}{|l|}{$95 \% \mathrm{Cl}$} & \multicolumn{3}{|c|}{$95 \% \mathrm{CI}$} & \multicolumn{3}{|c|}{$95 \% \mathrm{CI}$} \\
\hline & & $\begin{array}{l}\text { Lower } \\
\text { limit }\end{array}$ & $\begin{array}{l}\text { Upper } \\
\text { limit }\end{array}$ & $\begin{array}{l}\text { Estimated } \\
\text { value }\end{array}$ & $\begin{array}{l}\text { Lower } \\
\text { limit }\end{array}$ & $\begin{array}{l}\text { Upper } \\
\text { limit }\end{array}$ & $\begin{array}{l}\text { Estimated } \\
\text { value }\end{array}$ & Lower limit & $\begin{array}{l}\text { Upper } \\
\text { limit }\end{array}$ \\
\hline Prevalence & $16.2 \%$ & 0.127 & 0.204 & $18.8 \%$ & 0.150 & 0.221 & $25.6 \%$ & 0.213 & 0.303 \\
\hline Sensitivity & $87.1 \%$ & 0.756 & 0.939 & $84.2 \%$ & 0.732 & 0.915 & $82.7 \%$ & 0.734 & 0.893 \\
\hline NPV & $96.90 \%$ & 0.938 & 0.986 & $95.7 \%$ & 0.922 & 0.977 & $93.4 \%$ & 0.895 & 0.960 \\
\hline $\mathrm{LR}+$ & 3.938 & 3.140 & 4.939 & 4.560 & 3.526 & 5.898 & 5.354 & 4.020 & 7.129 \\
\hline LR- & 0.166 & 0.087 & 0.317 & 0.193 & 0.112 & 0.332 & 0.205 & 0.133 & 0.316 \\
\hline
\end{tabular}

*PPV: statistically different $p<0.001$ for all three comparisons ( 1 vs 3 days, 1 vs 5 days, 3 vs 5 days).

DEMO, DElirium MOdel; LR, likelihood ratio; NPV, negative predictive value; PPV, positive predictive value. 
3 days, 1 vs 5 days, 3 vs 5 days), NPV was not statistically different $\mathrm{p}=0.25,0.004,0.031$ for 1 vs 3 days, 1 vs 5 days and 3 vs 5 days, respectively.

Patients who developed delirium within 5 days were significantly older (mean age 83.9 (SD 7.8)) compared with those who did not develop a delirium within 5 days (mean age 73.9 (SD 9.1); $\mathrm{p}<0.001$ ). There was no significant difference in the percentage of males within the delirium and non-delirium groups $(50.0 \%$ vs $50.1 \%$, $\mathrm{p}=0.911$ ).

\section{DISCUSSION AND CONCLUSION}

In the current study, a previously developed model for predicting delirium has been validated. DEMO was calculated prospectively, and the outcome was ascertained by chart review retrospectively. Based on the current data and the high sensitivity and specificity, it can be concluded that DEMO is a satisfactory prediction model.

Another strength of DEMO is that it predicts delirium within 5 days postanalysis on a daily basis. This is a novel concept, as most delirium prediction rules apply at admission but not daily. Even though it is not clear whether there is a definite advantage to predicting delirium on a daily basis, as this could lead to information overload, it could eventually be something that is tracked along with vital signs and intake/output.

We found sensitivity and specificity rates that were higher than reported in the study by de Wit $e t a l$, which may be because his study only checked the patients' medical history for delirium and not the entire EPR. Moreover, de Wit $e t$ al had performed the search merely on the diagnosis of delirium. In the current study, the full EPR during the admission period was taken into account, and a wider set of terms was considered for delirium diagnosis. Furthermore, in the current study, in those cases in which delirium was not clear, these patients were excluded, whereas such patients had been included in the development of the delirium model. ${ }^{4}$

The present study does present some limitations. First, the validation of the DEMO depends on how and when a healthcare professional reports that a patient has developed delirium. It is well known that documentation of delirium is poor since the majority of delirium remains unrecognised by clinical teams. ${ }^{37}$ We therefore performed a wider search considering other words that might suggest delirium as delirium diagnosis and read through the whole EPR during the admission period. The number of delirium patients is noticeably higher than originally found, which can be explained by the search we performed. The DEMO is merely an aid to detect delirium, not a diagnostic tool by itself. Furthermore, for 46 patients there was insufficient information in the chart to determine delirium status, which could influence the generalisability of the present study.

In addition, as mentioned in the study by Inouye et $a l^{38}$ using a chart review method has some limitations as it has a $30 \%$ false-positive rate and thus it is possible that patients with delirium at admission may have been included in the non-delirious cohort due to poor documentation in the chart.

Furthermore, the checklist used to screen the patients is a non-validated tool. Nevertheless, after that first check, the DOSS is used. The DOSS method is a validated method used by nurses to screen for delirium. Its sensitivity ranges from $89 \%$ to $100 \%$ and its specificity ranges from $88 \%$ to $96.6 \% .{ }^{20} 3940$ The DOSS scores and its conclusion (delirium/non-delirium) are recorded in the chart. In that way, and taking into account that the chart is a complete document in which different healthcare professionals note their findings, makes the outcome more reliable and strengthens the validity of the present study.

Another limitation of the present study is that this is a single-centre study (two hospital locations) located in the Netherlands and may not be generalisable in other settings.

The DEMO uses only electronically available data. Other important factors that could predict a delirium (previous delirium, cognitive impairment, severity of disease, visual impairment, etc) are not included in this model because they were not electronically available. If these data were also made electronically available, the predictive quality of DEMO could be improved. ${ }^{22} 232730$ Taking into account that the registration of such factors is becoming increasingly important and mandatory, it is only a matter of time until these important factors can be used in the DEMO. ${ }^{23}$ In addition, DEMO already uses an alternative way of identifying cognitive impairment by including medications used for dementia.

The DEMO is a fully automated satisfactory prediction model that predicts delirium up to 5 days after analysis. The next step is to validate the DEMO in a cohort in which the outcome of delirium would be prospectively assessed in person and to use DEMO for retrospective measurements. In the future, DEMO will be applied to clinical practice so that physicians are alerted when a patient is at increased risk of developing delirium. This will facilitate earlier recognition and diagnosis and, thus, the implementation of prevention measures.

\section{Author affiliations}

${ }^{1}$ Department of Clinical Pharmacy, Pharmacology and Toxicology, Zuyderland Medical Centre, Sittard-Geleen, The Netherlands

${ }^{2}$ Department of Clinical Pharmacy, Elkerliek Hospital, Helmond, The Netherlands ${ }^{3}$ Department of Clinical Pharmacy, Canisius Wilhelmina Hospital, Nijmegen, The Netherlands

${ }^{4}$ Section of Geriatric Medicine, Department of Internal Medicine, Zuyderland Medical Centre, Sittard-Geleen, The Netherlands

${ }^{5}$ Department of Internal Medicine, Maastricht University Medical Centre, Maastricht, The Netherlands

${ }^{6}$ Department of Family Medicine and Department of Health Services Research, CAPHRI-School for Public Health and Primary Care, Maastricht University, Maastricht, The Netherlands

${ }^{7}$ Department of Psychiatry and Neuropsychology, Alzheimer Centrum Limburg/ School for Mental Health and Neurosciences, Maastricht University, Maastricht, The Netherlands

${ }^{8}$ Department of Methodology and Statistics, CAPHRI-School for Public Health and Primary Care, Maastricht University, Maastricht, The Netherlands 
${ }^{9}$ Department of Hospital Pharmacy, Erasmus Medical Center, Rotterdam, The Netherlands

Contributors All authors have made substantial contributions to conception and design, acquisition of data, analysis and interpretation of data. They all have been involved in drafting the manuscript and revising it critically for important intellectual content. They all have given final approval of the version to be published; and they all agree to be accountable for all aspects of the work in ensuring that questions related to the accuracy or integrity of any part of the work are appropriately investigated and resolved. Conception or design of the work: CMG, HAJMdW, BPCV0, DSD, KPGMH, WJM, RJ, JMGAS, FRV, BW, PHMvdK. Data collection: CMG, DSD, KPGMH. Data analysis and interpretation: CMG, KPGMH, FRV, BW, PHMvdK. Drafting the article: CMG. Critical revision of the article: HAJMdW, BPCV0, JMGAS, FRV, BW, PHMvdK. Final approval of the version to be published: CMG, HAJMdW, BPCv0, DSD, KPGMH, WJM, RJ, JMGAS, FRV, BW, PHMvdK.

Funding This work was supported by ZonMw (the Netherlands Organisation for Health Research and Development) grant number (113101001).

Competing interests None declared.

Ethics approval The medical ethics committee METC Z (Medisch Ethische Toetsings Commissie van Zuyderland en Zuyd Hogeschool, Zuyderland Medical Centre, Heerlen) approved this study.

Provenance and peer review Not commissioned; externally peer reviewed.

Data sharing statement All data are anonymised and will be confidentially handled. Only the investigators have access to the data. All patient data will be kept for as long as the project is being conducted.

Open Access This is an Open Access article distributed in accordance with the Creative Commons Attribution Non Commercial (CC BY-NC 4.0) license, which permits others to distribute, remix, adapt, build upon this work non-commercially, and license their derivative works on different terms, provided the original work is properly cited and the use is non-commercial. See: http://creativecommons.org/ licenses/by-nc/4.0/

(C) Article author(s) (or their employer(s) unless otherwise stated in the text of the article) 2017. All rights reserved. No commercial use is permitted unless otherwise expressly granted.

\section{REFERENCES}

1. Inouye SK, Westendorp RG, Saczynski JS. Delirium in elderly people. Lancet 2014;383:911-22.

2. National Institute for Health and Care Excellence. Delirium: diagnosis, prevention and management: NICE guidelines [CG103], 2010.

3. Delirium for Adults Dutch Guideline. Richtlijn Delier Volwassenen. Nederlandse Vereniging voor Klinische Geriatrie, 2013

4. de Wit HA, Winkens B, Mestres Gonzalvo C, et al. The development of an automated ward independent delirium risk prediction model. Int J Clin Pharm 2016;38:915-23.

5. Siddiqi N, House AO, Holmes JD. Occurrence and outcome of delirium in medical in-patients: a systematic literature review. Age Ageing 2006;35:350-64.

6. Ryan DJ, O'Regan NA, Caoimh RÓ, et al. Delirium in an adult acute hospital population: predictors, prevalence and detection. BMJ Open 2013;3:e001772.

7. Inouye SK. Delirium in hospitalized older patients. Clin Geriatr Med 1998;14:745-64.

8. Bruce AJ, Ritchie CW, Blizard R, et al. The incidence of delirium associated with orthopedic surgery: a meta-analytic review. Int Psychogeriatr 2007;19:197-214.

9. Girard TD, Ely EW. Delirium in the critically ill patient. Handb Clin Neurol 2008;90:39-56.

10. Inouye SK. Delirium in older persons. N Engl J Med 2006;354:1157-65.

11. Pisani MA, McNicoll L, Inouye SK. Cognitive impairment in the intensive care unit. Clin Chest Med 2003;24:727-37.

12. Leslie DL, Marcantonio ER, Zhang Y, et al. One-year health care costs associated with delirium in the elderly population. Arch Intern Med 2008;168:27-32.

13. Salluh Jl, Wang $\mathrm{H}$, Schneider EB, et al. Outcome of delirium in critically ill patients: systematic review and meta-analysis. BMJ 2015;350:h2538

14. WHO Regional Office for Europe. European hospital morbidity database. Copenhagen: World Health Organization, 2012.
15. Organisation for Economic Co-operation and Development. $O E C D$ health data 2012. Paris: Organisation for Economic Co-operation and Development, 2012.

16. Adamis D, Sharma N, Whelan PJ, et al. Delirium scales: a review of current evidence. Aging Ment Health 2010;14:543-55.

17. Wong CL, Holroyd-Leduc J, Simel DL, et al. Does this patient have delirium?: value of bedside instruments. JAMA 2010;304:779-86.

18. Inouye SK, van Dyck $\mathrm{CH}$, Alessi $\mathrm{CA}$, et al. Clarifying confusion: the confusion assessment method. A new method for detection of delirium. Ann Intern Med 1990;113:941-8.

19. Han JH, Vasilevskis EE. Ultrabrief delirium assessments-are they ready for primetime? J Hosp Med 2015;10:694-5.

20. Schuurmans MJ, Shortridge-Baggett LM, Duursma SA. The Delirium observation screening scale: a screening instrument for delirium. Res Theory Nurs Pract 2003:17:31-50.

21. van Velthuijsen EL, Zwakhalen SM, Warnier RM, et al. Psychometric properties and feasibility of instruments for the detection of delirium in older hospitalized patients: a systematic review. Int $J$ Geriatr Psychiatry 2016;31:974-89.

22. Laurila JV, Laakkonen ML, Laurila JV, et al. Predisposing and precipitating factors for delirium in a frail geriatric population. J Psychosom Res 2008;65:249-54.

23. Inouye SK. Predisposing and precipitating factors for delirium in hospitalized older patients. Dement Geriatr Cogn Disord 1999:10:393-400.

24. AGS/NIA Delirium Conference Writing Group, Planning Committee and Faculty. The American Geriatrics Society/National Institute on aging bedside-to-bench conference: research agenda on Delirium in older adults. J Am Geriatr Soc 2015;63:843-52.

25. Neufeld KJ, Yue J, Robinson TN, et al. Antipsychotic Medication for Prevention and Treatment of Delirium in Hospitalized Adults: A Systematic Review and Meta-Analysis. J Am Geriatr Soc 2016;64:705-14.

26. Hipp DM, Ely EW. Pharmacological and nonpharmacological management of delirium in critically ill patients. Neurotherapeutics 2012;9:158-75

27. Young J, Leentjens AF, George J, et al. Systematic approaches to the prevention and management of patients with delirium. J Psychosom Res 2008:65:267-72.

28. Teslyar P, Stock VM, Wilk CM, et al. Prophylaxis with antipsychotic medication reduces the risk of post-operative delirium in elderly patients: a meta-analysis. Psychosomatics 2013:54:124-31.

29. Kalisvaart KJ, de Jonghe JF, Bogaards MJ, et al. Haloperidol prophylaxis for elderly hip-surgery patients at risk for delirium: a randomized placebo-controlled study. J Am Geriatr Soc 2005;53:1658-66.

30. Kishi T. Antipsychotic medications for the treatment of delirium: a systematic review and meta-analysis of randomised controlled trials. J Neurol Neurosurg Psychiatry 2016;87:767-74.

31. van den Boogaard M, Pickkers P, Slooter AJ, et al. Development and validation of PRE-DELIRIC (PREdiction of DELIRium in ICu patients) delirium prediction model for intensive care patients: observational multicentre study. BMJ 2012;344:e420.

32. Inouye SK, Viscoli CM, Horwitz RI, et al. A predictive model for delirium in hospitalized elderly medical patients based on admission characteristics. Ann Intern Med 1993;119:474-81.

33. Carrasco MP, Villarroel L, Andrade M, et al. Development and validation of a delirium predictive score in older people. Age Ageing 2014;43:346-51.

34. Douglas VC, Hessler CS, Dhaliwal G, et al. The AWOL tool: derivation and validation of a delirium prediction rule. J Hosp Med 2013;8:493-9.

35. Veiligheids Agenda. Platform voor patiëntveiligheid. http://www. vmszorg.nl/ (accessed 20 Jun 2017).

36. Richtlijn delier Volwassen en ouderen. Guideline delirium adults and elderly (Richtlijn delier volwassen en ouderen). 2013 http://www. vmszorg.nl/_library/24018/Richtlijn\%20Delier\%20Volwassenen\% 20en\%20ouderen\%202014.pdf

37. Collins N, Blanchard MR, Tookman A, et al. Detection of delirium in the acute hospital. Age Ageing 2010;39:131-5.

38. Inouye SK, Leo-Summers L, Zhang Y, et al. A chart-based method for identification of delirium: validation compared with interviewer ratings using the confusion assessment method. J Am Geriatr Soc 2005;53:312-8.

39. Gemert van LA, Schuurmans MJ. The Neecham confusion scale and the Delirium observation screening scale: capacity to discriminate and ease of use in clinical practice. BMC Nurs 2007;6:3.

40. Koster S, Hensens AG, Oosterveld FG, et al. The delirium observation screening scale recognizes delirium early after cardiac surgery. Eur J Cardiovasc Nurs 2009;8:309-14. 